\title{
SYNTHESIS OF CERAMICS TITANIUM COMPOUNDS BY MECHANICAL ALLOYING OF TIB2-TIN SYSTEMS
}

\author{
${ }^{1}$ Mikhail TROTSKY, ${ }^{1}$ Sergey PETROVICH, ${ }^{1}$ Valentina ANDREEVA, ${ }^{1}$ Anatoly POPOVICH \\ ${ }^{1}$ Maxim ZAMOZDRA \\ ${ }^{1}$ Peter the Great St. Petersburg polytechnic university, St.Petersburg, Russia, \\ m trotsky.ru@mail.ru
}

https://doi.org/10.37904/metal.2021.4204

\begin{abstract}
In recent years, there has been an increased interest in technologies for the production of titanium ceramic materials with properties, the level of which in terms of price-quality ratio exceeds the level of similar materials based on other metals. The strength of the bond with the metal in modern titanium ceramic products corresponds to the level of cermet systems based on noble metals or alloys without them. This work describes a method of obtaining and some properties of ceramic compounds based on titanium, such as TiBN by mechanical alloying. Heat treatment and spark plasma sintering were also carried out. The hardness of the obtained samples was determined and an X-ray phase analysis was carried out, which confirmed the presence of such phases as and $\mathrm{Ti}_{3} \mathrm{~B}_{2} \mathrm{~N}$.
\end{abstract}

Keywords: Mechanosynthesis, spark-plasma sintering, titanium-based compounds, wear-resistant coatings, corrosion-resistant coatings, ceramic materials

\section{INTRODUCTION}

Ceramic materials based on titanium - its carbide, nitride, and boride - themselves have a high complex of properties, but their derivatives - carbonitrides, carboborides, oxynitroborides, and others - often inherit not only all the valuable and often unique properties of their predecessors but also acquire a new the level of previous properties (for example, strength or electrical) or a surge of other properties that their predecessors did not possess. It is enough to give an example of titanium oxynitride, which has already been successfully tested as implants of the organs of the cardiovascular system, although its "components" - nitride and oxide could not be used in this area.[1]

Composite materials, in which carbides, nitrides, carbonitrides, titanium borides are used as a hardening medium, are dispersion-hardened (DHCM). Both the DHCM themselves and their coatings applied to other materials are capable of operating under high mechanical loads, elevated temperatures, and in aggressive environments. DHCM coatings of the Me / TiX system are most in demand for structural applications with energy-intensive operating conditions.

An increase in the requirements for the operational properties of coatings requires the search for new types of solid phase as a wear-resistant component, which are not inferior in hardness and heat resistance to carbides, but have a higher melting point and plasticity. Among such compounds, a special place is occupied by oxygenfree refractory compounds, including titanium carbonitrides, the use of which in the creation of surfacing materials is now increasingly expanding.

Interest in nitroboride coatings arises from the fact that they are usually multiphase. Such systems have much in common with composite materials and often exhibit higher hardness and toughness values than single- 
phase materials. TiBN coatings of various compositions were obtained in [3] by sputtering from composite targets at a substrate temperature of $20^{\circ} \mathrm{C}$. All films had a dense structural morphology. The TiBN0.5 coatings demonstrated a combination of high hardness and ductility. Annealing at $400^{\circ} \mathrm{C}$ for 6 hours increased the hardness and ductility by $40-50 \%$. The reaction of titanium with boron nitride can lead to the formation of titanium nitroborides. The heat of formation of products is higher than the heat of formation of the starting materials, and the process will be exothermic. The resulting compound can be applied to titanium alloys and steels to improve the surface properties of the structure, such as sealing the surface of a mold, which can improve machining efficiency and tool life. Ti3B2N can also be used for the manufacture of DHCM. Superhard (up to $55 \mathrm{GPa}$ ) coatings of the Ti-B-N system of variable composition were obtained by sputtering a target, which is a boron nitride plate coated with Ti powder.

\section{MATERIALS AND METHODS}

Mechanosynthesis was carried out in high-energy mills - attritors. The following materials were chosen as the starting compounds - titanium boride and titanium nitride. The charge for TiBN production is shown in (Table 1).

Table 1 The chemical composition of the $\mathrm{T}_{3} \mathrm{~B}_{2} \mathrm{~N}$ compound

\begin{tabular}{|c|c|c|}
\hline \multirow{2}{*}{ Powder sample } & \multicolumn{2}{|c|}{ Composition, mass. \% } \\
\hline \multirow{2}{*}{$\mathrm{Ti}_{3} \mathrm{~B}_{2} \mathrm{~N}$} & $\mathrm{TiB}_{2}$ & $\mathrm{TiN}$ \\
\cline { 2 - 3 } & 25 & 75 \\
\hline
\end{tabular}

The titanium nitroboride compound with the stoichiometry indicated in (Table 1), according to the literature, has an increased Vickers hardness and is approximately from $28 \mathrm{GPa}$, which is higher than that of crystalline titanium carbide $(\mathrm{TiC})$, zirconium carbide $(\mathrm{ZrC})$, titanium nitride ( $\mathrm{TiN})$.

The experiment was carried out as follows: the mixture was subjected to stage-by-stage mechanical treatment in an attritor. After 2000 seconds, the mill was stopped to cool the reaction mixture and ball charge. The processing time of the material in the mill was 10 hours.

After mechanical synthesis, the resulting material was subjected to spark plasma sintering.

Heat treatment was carried out in the following mode: pressing the press powder without heating with a pressure of $5 \mathrm{kN}$, when heated to $1800^{\circ} \mathrm{C}$, the pressure was raised to $15 \mathrm{kN}$ and held at this value for 5 minutes. As a result, a sample of a pressed tablet with a diameter of $12 \mathrm{~mm}$ and a height of $6 \mathrm{~mm}$ was obtained. Then the resulting tablet was analyzed using and microhardness measurements (Table 2).

\section{RESULTS AND DISCUSSION}

\subsection{Obtaining $\mathrm{Ti}_{3} \mathrm{~B}_{2} \mathrm{~N}$ - compound by mechanical alloying.}

After mechanical treatment, the product was investigated using the X-ray photoelectron spectroscopy (XPS) method implemented in the SPECS equipment (Germany). The energy scale is calibrated against the Au4f7 / 2 gold line, which is equal to $84.00 \mathrm{eV}$, and using X-ray phase analysis (XPA) on a D8 Advance from Bruker (Germany) using monochromatic CuKa radiation $(\lambda=1.54178 \AA)$, with a scanning step of $0.02{ }^{\circ}$ and an exposure of 11 using scanning electron microscopy. The ICDD powder database (PDF-2) was used for phase analysis. The structure of the resulting phases was refined by the Rietveld method in the programmed introduction of DIFFRACplus Topas using the data of the ICSD structural database. 


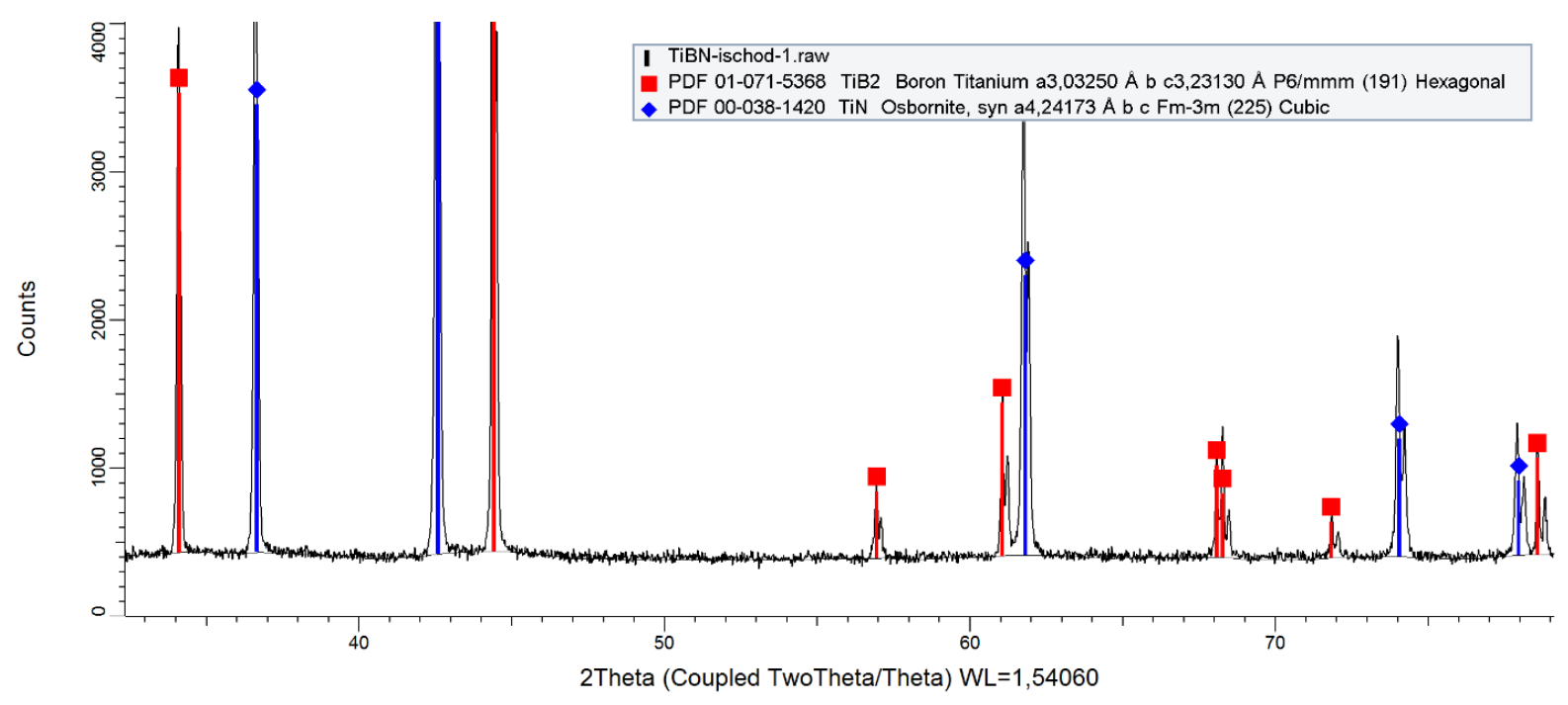

Figure 1 Diffraction pattern of the initial TiB-TiN mixture

In the presented diffraction pattern (Figure 1) of the mechanical mixture of the initial components before processing, one can see noticeable peaks of the initial components. It can be noted that the peaks of the initial components have a high intensity value and an unbroken shape of the peak itself, which indicates an unchanged crystal structure.

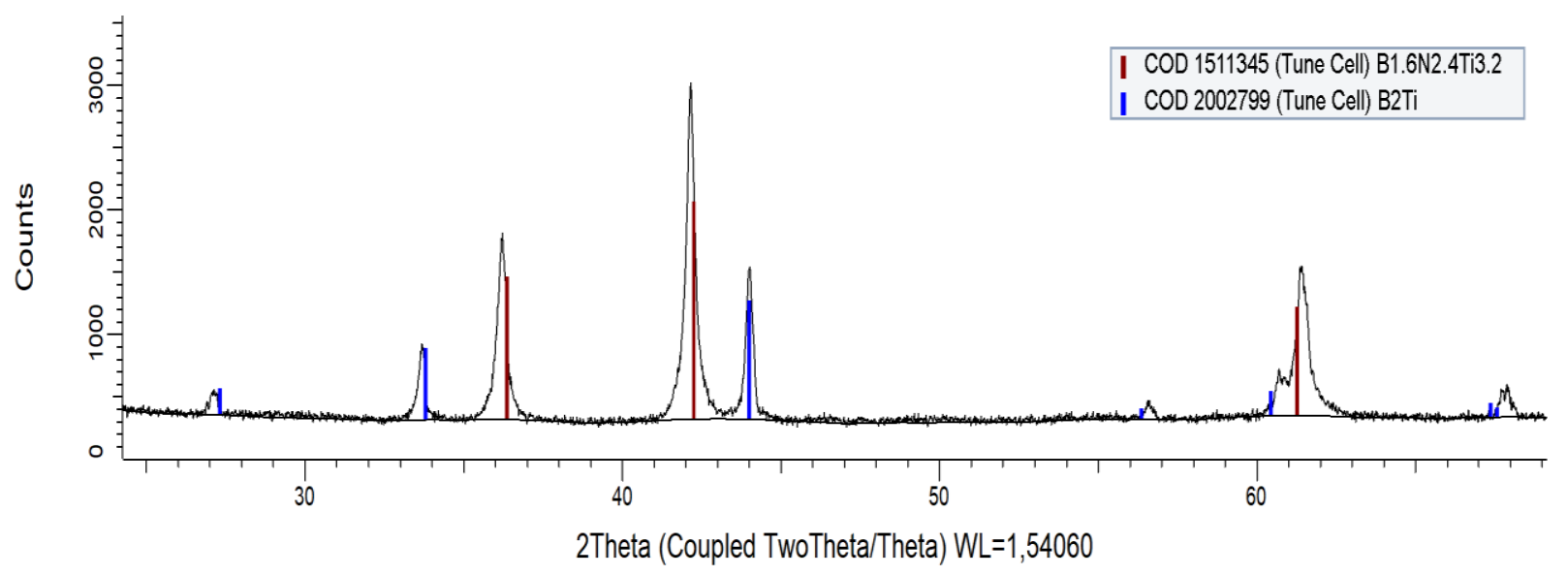

Figure 2 Diffraction pattern of the $\mathrm{Ti}_{3} \mathrm{~B}_{2} \mathrm{~N}$ mixture after 10 hours of mechanosynthesis

As can be seen from the diffraction pattern of the obtained sample, after 10 hours of mechanical synthesis (Figure 2), the compound $\mathrm{B}_{1.6} \mathrm{~N}_{2.4} \mathrm{Ti}_{3.2}$ is formed. Broadening of the peaks can be seen due to an increase in the number of microstrains and a change in the crystal lattice.

Subsequently, the material was subjected to heat treatment in an oven in an argon atmosphere at a temperature of $1600^{\circ} \mathrm{C}$ for 2 hours. After heat treatment, the sample was tested for strength by the Vickers method.

\subsection{Heat treatment of the Ti3B2N compound by spark plasma sintering and determination of the hardness of the resulting material}

Carrying out the reaction under adiabatic conditions makes it possible to obtain Ti-BbNc compounds under high-temperature sintering. The last method was used to obtain a new crystalline structure Ti3B2N, the 
material of which has an increased Vickers hardness ( $\geq 28 \mathrm{GPa})$, which is higher than that of crystalline titanium carbide $\mathrm{TiC}$, zirconium carbide $\mathrm{ZrC}$, titanium nitride $\mathrm{TiN}$.

Heat treatment was carried out in the following mode: pressing the press powder without heating with a pressure of $5 \mathrm{kN}$, when heated to $1800^{\circ} \mathrm{C}$, the pressure was raised to $15 \mathrm{kN}$ and held at this value for 5 minutes. As a result, a sample of a pressed tablet with a diameter of $12 \mathrm{~mm}$ and a height of $6 \mathrm{~mm}$ was obtained. Then the resulting tablet was analyzed using XRD (Figure 3) and microhardness measurements (Table 2).

The sample was split into several pieces of different sizes (Figure 2). The pieces were molded into acrylic resin. Before testing, the surfaces of the samples were prepared by grinding with abrasive SiC papers (400 to 1200 grit) followed by polishing with diamond suspension (9 to $3 \mu \mathrm{m}$ ).

The microhardness profiles of the sample were measured using a Buehler Micromet hardness test machine with a Vickers tip. Microhardness values for pieces (Table 2) was obtained using a load of $1000 \mathrm{~g}$ (HV1). The microhardness of the sample was measured in accordance to ISO 6507-1: 2018.

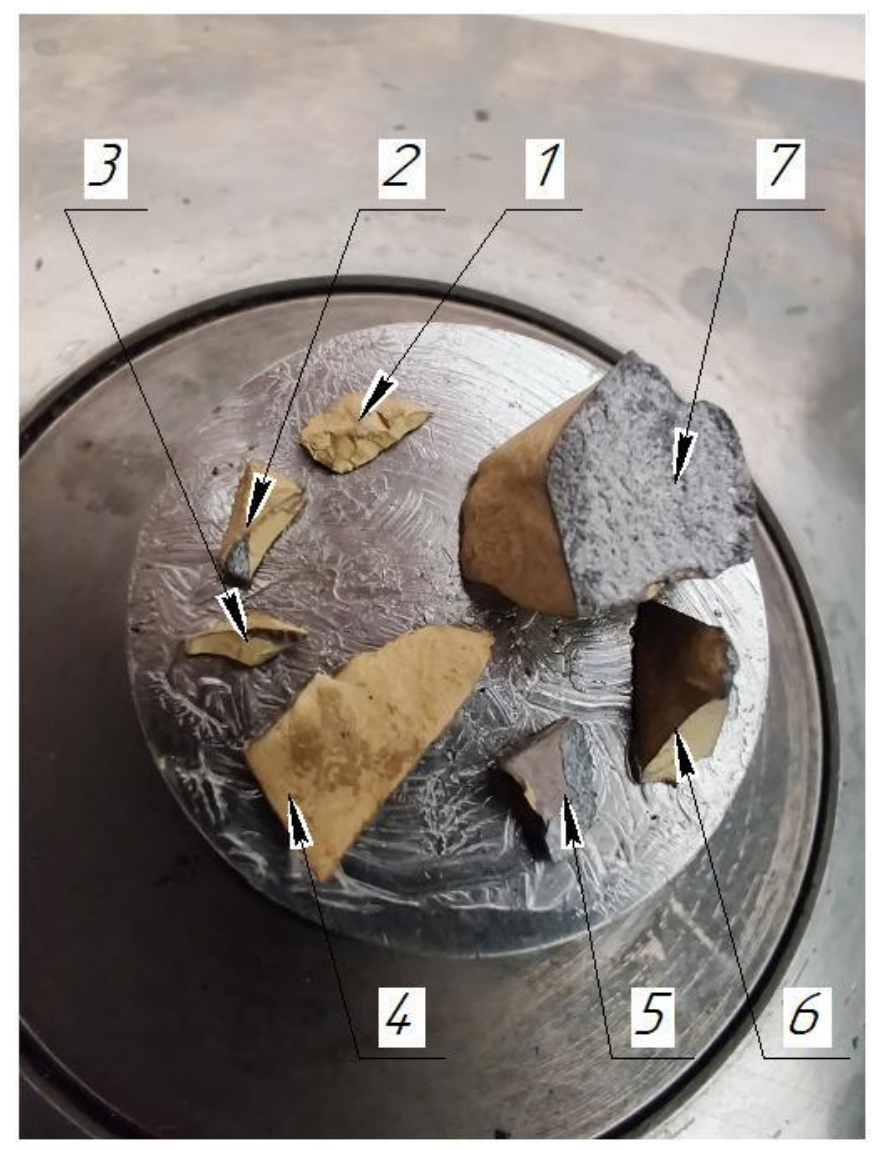

Figure 3 Image of samples pieces (1-7) after spark plasma sintering split into parts to determine the microhardness of the material.

Table 2 The microhardness profiles of the SPS sample, measured for different pieces

\begin{tabular}{|c|c|c|c|c|c|c|}
\hline Samples piece & $\mathbf{1}$ & $\mathbf{2}$ & $\mathbf{4}$ & $\mathbf{5}$ & $\mathbf{6}$ & $\mathbf{7}$ \\
\hline \multirow{3}{*}{ Microhardness value, MPa } & 1656 & 1622 & 2195 & 1775 & 2079 & 1512 \\
\cline { 2 - 7 } & 1514 & 1785 & 1776 & 1789 & 1641 & 1848 \\
\cline { 2 - 7 } & 1463 & 1632 & 1649 & 1906 & 1696 & 2165 \\
\hline Average, MPa & 1544.3 & 1679.7 & 1873.3 & 1823.3 & 1805.3 & 1841.7 \\
\hline
\end{tabular}


The measurement was performed 5 times for each part, after which the largest and smallest values were discarded. As we can see, the range of values is from $1463 \mathrm{MPa}$ to $2195 \mathrm{MPa}$ and on average is $1761 \mathrm{MPa}$.

\section{CONCLUSION}

Based on this work, it can be concluded that it is in principle possible to connect titanium nitroborides, namely, the $\mathrm{B}_{1.6} \mathrm{~N}_{2.4} \mathrm{Ti}_{3.2}$ compound, which is stoichiometrically similar to the $\mathrm{Ti}_{3} \mathrm{~B}_{2} \mathrm{~N}$ compound. The presence of such stoichiometry indicates that 10 hours of mechanical treatment is not enough for the synthesis of $\mathrm{Ti}_{3} \mathrm{~B}_{2} \mathrm{~N}$. The hardness of the material after spark plasma sintering was also determined. The hardness range values from $1463 \mathrm{MPa}$ to $2195 \mathrm{MPa}$ and on average is $1761 \mathrm{MPa}$.

\section{ACKNOWLEDGEMENTS}

\section{The reported study was funded by RFBR, project number 20-33-90103}

\section{REFERENCES}

[1] TROTSKY, M., PETROVICH, S., ZAMOZDRA, M., WANG, Q.S. Study of the phase evolution during the mechanical alloying of the TiN-TiC-TiB2-TiO2 system. In: Materials Today: Proceedings. 2020, pp. 490-495.

[2] GONCHAROV I., RAZUMOV N., SHAMSHURIN A., WANG, Q.S. Effect of the Mechanical Alloying and Spark Plasma Sintering on Microstructure, Phase Composition and Chemical Elements Distribution of $\mathrm{Nb}-\mathrm{Si}$ Based Composite. Key Engineering Materials. 2019, pp. 617-627.

[3] RAZUMOV, N., POPOVICH, A., GRIGOR'EV, A., SILIN, A., GONCHAROV, I. Morphology of High-Strength HeatResistant Steel Powder for Machines for Additive Production from Shavings. Metal Science and Heat Treatment. 2019, pp. 1-5.

[4] GONCHAROV, I., RAZUMOV, N., SILIN, A., OZERSKOI, N., SHAMSHURIN, A., KIM, A., WANG, Q.S., $\mathrm{POPOVICH}, \mathrm{A}$. Synthesis of $\mathrm{Nb}$-based powder alloy by mechanical alloying and plasma spheroidization processes for additive manufacturing. Materials Letters. 2019.

[5] POPOVICH, A., RAZUMOV, N. Dissolution of Alloying Elements and Powder Materials Fe-18Cr-8Ni-12Mn-xN During Mechanichal Alloying. Advanced Materials Letters. 2014, vol. 5, no. 12, pp. 683-687.

[6] POPOVICH, A. Mechanochemical synthesis of high-alloyed powder alloys of the Fe-Cr-Ni-Mn-N system. Russian Journal of Non-Ferrous Metals. 2013, vol. 54, no. 6, pp. 508-512. 